\title{
ERODED PLASTIC PELLETS AS MONITORING TOOLS FOR POLYCYCLIC AROMATIC HYDROCARBONS (PAH): LABORATORY AND FIELD STUDIES
}

\author{
KARAPANAGIOTI H.K. ${ }^{1, *}$ \\ OGATA Y. ${ }^{2}$ \\ TAKADA H. ${ }^{2}$
}

Received: $10 / 01 / 10$

Accepted: 27/08/10

\author{
${ }^{1}$ Department of Chemistry, University of Patras \\ 26500 Rio-Patras, Greece \\ ${ }^{2}$ Laboratory of Organic Geochemistry \\ Tokyo University of Agriculture and Technology, Tokyo, Japan
}

*to whom all correspondence should be addressed: e-mail: karapanagioti@upatras.gr

\begin{abstract}
Through transportation accidents or intentional releases, plastic pellets (small granules 1-5 mm in diameter) are widely distributed in the ocean all over the world. These pellets accumulate organic pollutants and can be used for the determination of diffusive seawater pollution. Pellets demonstrating a certain degree of erosion are expected to have enough contact time with the water pollutants and thus, reach sorption equilibrium with the water phase. In the present study, eroded pellets collected from Greek beaches, were separated into polyethylene (PE) and polypropylene (PP). Polycyclic aromatic hydrocarbons (PAHs, i.e. naphthalene, phenanthrene, and pyrene) were used as model compounds to study the uptake kinetics into these eroded pellets. Naphthalene uptake demonstrates similar kinetics in both eroded PE and PP. Phenanthrene and pyrene uptake demonstrates slower kinetic rates by eroded PE than by virgin PE and similar kinetic rates by eroded and virgin PP. These observations are then used to evaluate PAHs measurements in pellets sampled from two sampling sites in Saronikos Gulf. It is concluded that seawater in Loutropyrgos beach is polluted by PAHs more than seawater in Aegena island. PAH pollution in both sampling sites is of pyrogenic origin.
\end{abstract}

KEYWORDS: Polyethylene, polypropylene, organic pollutant diffusion, $\mathrm{PAH}$, pollution monitoring, Saronikos Gulf.

\section{INTRODUCTION}

Plastic pellets (small granules 1-5 millimeters in diameter) are raw material used for the production of many different plastic products. They are widely distributed in the ocean all over the world. These plastic pellets are unintentionally released to the marine environment during manufacturing and transportation. Since they are organic polymers they sorb organic pollutants on their surface or into their matrix (Karapanagioti and Klontza, 2008). The environmental concerns related to these pellets is the accumulation of persistent organic compounds while they float on the sea surface (Mato et al., 2001; Endo et al., 2005) and then their ingestion by small marine animals such as sea turtles and birds (Azzarello and Van Vleet, 1987; Moser and Lee, 1992; Derraik and Jose, 2002).

Lately, there is an increasing interest in using these pellets as passive samplers for monitoring pollution throughout the world. Nowadays, monitoring media which can be easily collected and shipped with low cost is important for monitoring diffuse pollution. International Pellet Watch is a program aiming at global monitoring of persistent organic pollutants (POPs) in coastal waters. The initial phase on PCBs, DDTs, and HCHs measurements has been successfully completed (Ogata et al., 2009). Pellets are collected from different beaches, they are shipped to specialized laboratories that sort them by polymer material and then, the pollutants are extracted and analyzed. Pellets demonstrating a certain degree of erosion, are expected to have enough contact time with the water pollutants and thus, reach equilibrium with the pollutant in the water phase (Karapanagioti and Klontza, 2008; Ogata et al., 2009). To improve the usefulness of pellet as passive sampler, 
understanding the temporal resolution of pellet watch monitoring (days, months, years or decades) is important. That is, we should know the period for which pollutant concentration in pellets would reach equilibrium with those in surrounding sea water or time-span for which pellets reflect the pollution status in sea water. Study on the sorption kinetics is the key to address the questions.

In the present study, sorption kinetic experiments are performed with sorted beach pellets in order to better understand the sorption kinetics of the different polymer materials [i.e. polyethylene (PE) and polypropylene (PP)] and different size molecules of polycyclic aromatic hydrocarbon compounds (PAHs) (i.e. naphthalene, phenanthrene, and pyrene). Based on these experimental results, the data on PAH concentrations measured in pellets collected at two different sampling sites in Saronikos Gulf are evaluated. PAHs are a class of pollutants that are found in most polluted marine areas (Lipiatou and Saliot, 1991; Cornelissen and Gustafsson, 2004; Kostopoulou et al., 2007; Valavanidis et al., 2008; Karapanagioti et al., 2009) and originate from pollution due to oil spills and/or combustion of fossil fuels.

\section{MATERIALS AND METHODS}

Plastic pellets were sampled from one location in Patraikos Gulf: Kato Achaia $\left(38^{\circ} 09^{\prime} 18^{\prime \prime} \mathrm{N}\right.$, $\left.21^{\circ} 33^{\prime} 00^{\prime \prime} \mathrm{E}\right)$ and two different locations in Saronikos Gulf: Loutropyrgos beach (38 $01^{\prime} 31^{\prime \prime} \mathrm{N}$, $\left.23^{\circ} 28^{\prime} 28^{\prime \prime} \mathrm{E}\right)$ and Aegena island $\left(37^{\circ} 43^{\prime} 30^{\prime \prime} \mathrm{N}, 23^{\circ} 31^{\prime} 53^{\prime \prime} \mathrm{E}\right)$. In sandy beaches, plastic pellets can be easily found on the top of the sand. Samples were taken from the high tide line as well as from the berm or the upper part of the beach. After the pellets were separated from the sand, they were stored in aluminum foil and at $4^{\circ} \mathrm{C}$. They were shipped to Japan via airmail for further analysis.

The pellets were sorted by near-infrared spectrometer to select PE pellets and then, by naked eye to select yellowing PE which were proven to accumulate higher concentrations of non polar organic pollutants (Endo et al., 2005; Ogata et al., 2009). To consider piece-to-piece variation, 5 pools (each pool consists of 10 pieces of pellets) were analyzed for each location. Pellets were extracted with hexane by maceration. The extracts were purified by silica gel column chromatography. PAH concentrations were measured by a gas chromatograph equipped with ion-trap mass spectrometer on MS/MS mode. PAH concentrations in pellets from Kato Achaia were not statistically different from those in the blank solvents that were also analyzed in the same manner.

Sorted pellets from Kato Achaia, both PE and PP, were utilized in sorption kinetic experiments with single component solutions of 3 PAHs (i.e. naphthalene, phenanthrene, and pyrene). All sorption kinetic experiments were conducted in triplicate in $120 \mathrm{~mL}$ amber glass bottles with Teflon-coated septa. The initial concentrations were 300,100 , and $2 \mu \mathrm{L} \mathrm{L}^{-1}$ for naphthalene, phenanthrene, and pyrene, respectively. One pellet ( 0.031 and $0.023 \mathrm{~g}$ for $\mathrm{PE}$ and $\mathrm{PP}$, respectively) was added in each bottle. The bottles were stored at room temperature (around $23^{\circ} \mathrm{C}$ ) in the dark and shaken periodically. Measurements were taken at various time intervals (i.e., 1, 3, 7, 14, 30, 150 days) for eroded pellets in synthetic seawater. Aqueous single component $\mathrm{PAH}$ concentrations were measured by a Perkin-Elmer LS 50B variable wavelength fluorescence detector in cuvette mode. For each batch experiment, triplicate blank samples were prepared and monitored (e.g. phenanthrene without pellets). These blank samples did not indicate any significant PAH degradation or sorptive losses on the glassware for the duration of the experiment.

\section{DATA ANALYSIS}

The sorption distribution coefficient, $K_{d}\left(\mathrm{~L} \mathrm{Kg}^{-1}\right)$, is related to the aqueous solute concentration (C) and the mass of solute sorbed per unit mass of polymer pellet $\left(q_{\mathrm{e}}\right)\left[\left(\mu \mathrm{g} \mathrm{Kg}^{-1}\right)\right]\left(\mu \mathrm{g} \mathrm{L}^{-1}\right)$ by the following equation:

$K_{\mathrm{d}}=q_{\mathrm{e}} / C$

$K_{\mathrm{da}}$ is the apparent sorption distribution coefficient measured at a given time and not necessarily at equilibrium. The aqueous solute concentration $(C)$ was directly measured on every sampling occasion. The mass of solute sorbed per unit mass of polymer pellet $\left(q_{\mathrm{e}}\right)$ was determined for each sampling time through the following mass balance equation: 
$q_{e}=\frac{\left(C_{0}-C\right) V}{m}$

where $C_{0}$ is the initial concentration or the average solute solution concentration of the triplicate blank samples that corresponds to the triplicate samples, $\mathrm{V}$ is the sample solution volume, and $\mathrm{m}$ is the mass of the polymer pellet. Both $\mathrm{V}$ and $\mathrm{m}$ were recorded during sample preparation.

The distribution kinetic results are explained using Fick's $2^{\text {nd }}$ law in spherical coordinates for pellets:

$\frac{\partial \mathrm{C}}{\partial \mathrm{t}}=\frac{\mathrm{D}_{\mathrm{a}}}{\mathrm{r}^{2}} \frac{\partial}{\partial \mathrm{r}}\left(\mathrm{r}^{2} \frac{\partial \mathrm{C}}{\partial \mathrm{r}}\right)$

where $C$ is the solute concentration, $t$ is the time, $r$ is the distance from the center of the sphere and $D_{a}$ is the apparent diffusion coefficient.

If the distribution isotherm is linear and the initial and boundary conditions known, analytical solutions to the Fick's $2^{\text {nd }}$ law exist. Distribution experiments in batch reactors (bath of limited volume; Grathwohl, 1998) can be described with the following conditions:

$C=0$ at the beginning of the experiment $(\mathrm{t}=0)$ inside the pellet $(0<r<\alpha)$

$C=C_{\text {eq }}$ at the end of the experiment $(t=\infty)$ at the surface of the pellet

$\partial \mathrm{C} / \partial \mathrm{r}=0$ after the beginning of the experiment and in the pellet center $(r=0)$

where $C_{\mathrm{eq}}$ is the solute aqueous concentration at equilibrium and $\alpha$ is the pellet radius.

In the present study, the values of $\left(D_{a} t / \alpha^{2}\right)$, a dimensionless number also known as Fourier number, are lower than 0.1 for the time needed to reach equilibrium. These low Fourier numbers allow the use of a short-term approximation of the analytical solution given by Crank (Grathwohl, 1998) as has been successfully used in another study for the modeling of phenanthrene diffusion into virgin PE and PP pellets (Karapanagioti and Klontza, 2008):

$$
\frac{\mathrm{M}}{\mathrm{M}_{\mathrm{eq}}}=6\left(\frac{1}{\beta}+1\right) \sqrt{\frac{\mathrm{D}_{\mathrm{a}} \mathrm{t}}{\pi \alpha^{2}}}
$$

where $M / M_{e q}$ is the mass of solute in the pellet $(M)$ after time t over the same mass at equilibrium $\left(M_{\text {eq }}\right)$, and $\beta$ is the ratio of the solute mass in solution to the solute mass in the pellet at equilibrium (calculated from the experimental results at equilibrium e.g. mass of solute in solution is calculated through the solute aqueous concentration at equilibrium and the volume of the solution).

At non-equilibrium conditions solute sorptive uptake can be described by the ratio of the apparent distribution coefficient $\left(\mathrm{K}_{\mathrm{da}}\right)$ to the distribution coefficient at equilibrium $\left(\mathrm{K}_{\mathrm{d}}\right)$ as follows $(\mathrm{Grathwohl}$, 1998):

$$
\frac{\mathrm{K}_{\mathrm{da}}}{\mathrm{K}_{\mathrm{d}}}=\frac{\beta}{\frac{1+\beta}{\mathrm{M} / \mathrm{M}_{\mathrm{eq}}}-1}
$$

The advantage of Equation 5 compared to the previous Equation 4 describing the short term approximation is that the solution is independent of the different values of $\beta$ and allows comparison of the sorptive uptake at different solid-to-solution ratios in batch experiments (Grathwohl, 1998).

The fitting parameter in the analytical solution employed in the present study is $D_{\mathrm{a}}$. In an Excel spreadsheet, $K_{\mathrm{da}} / K_{\mathrm{d}}$ ratios were calculated through Equations 4 and 5 and were compared to experimental $K_{\mathrm{da}} / K_{\mathrm{d}}$ ratios for the experimental measurement times. The $D_{\mathrm{a}}$ value chosen is the one that minimizes the error given in Equation 6:

$$
\text { error }=\sum\left[\frac{\left(\text { average_measured } \frac{K_{d a}}{K_{d}}-\text { model } \frac{K_{d a}}{K_{d}}\right)}{\left(\operatorname{model} \frac{K_{d a}}{K_{d}}\right)}\right]^{2}
$$

that is the sum, of the mean of $\left(K_{\mathrm{da}} / K_{\mathrm{d}}\right.$ ratios measured) minus $\left(K_{\mathrm{da}} / K_{\mathrm{d}}\right.$ ratios predicted by the model $)$ over the $\left(K_{\mathrm{da}} / K_{\mathrm{d}}\right.$ ratios predicted by the model) squared, for all measurement times. 
For model result interpretation, $D_{\mathrm{e}}$ is defined as the effective diffusion coefficient independent of the distribution coefficient of each material that equals $D_{\mathrm{e}}=D_{\mathrm{a}} K_{\mathrm{d}} \rho$ (where $\rho$ is the particle density) and the effective diffusion rate independent of the particle radius is defined as $D_{\mathrm{e}} / \alpha^{2}$.

\section{RESULTS AND DISCUSSION}

Figure 1 presents the kinetic sorption curve for PE and three different PAH compounds. It seems that phenanthrene and pyrene, although different size compounds, have similar kinetic behaviour into the PE eroded pellets and similar $K_{d}$ equilibrium value. Naphthalene on the other hand reaches equilibrium faster and at a lower $K_{d}$ equilibrium value. Similar patterns are observed for PP and the three compounds (Figure 2). However the sorption kinetics for PP is faster than PE for all three compounds.

The sorption capacity of phenanthrene into PE has not reached equilibrium yet but its value compares well with values observed in other studies for eroded plastic pellets (Karapanagioti and Klontza, 2008). Based on the present experiments and previous literature values phenanthrene in PE could reach $90 \%$ of uptake equilibrium in $\sim 70-105$ days. For both phenanthrene and pyrene, PE demonstrates a sorption capacity 3-4 times higher than PP. Previous studies suggested that sorption onto PP is a surface mechanism and phenanthrene sorption into virgin PE was 30 times higher than onto virgin PP (Karapanagioti and Klontza, 2008). In the present study, phenanthrene sorption capacity of eroded PP is almost one order of magnitude higher than that of virgin PP (Karapanagioti and Klontza, 2008). Mato et al. (2001) observed $K_{d}$ values, for PCBs and marine eroded PP, 2 log units higher than $K_{d}$ values for virgin PP. Thus, the observed $K_{d}$ pattern in the present study is similar to $K_{d}$ pattern reported by Mato et al. (2001) for virgin and marine eroded PP. It is possible that erosion has increased PP surface area or has created diffusion pathways into the interior of the pellet and for this reason, phenanthrene sorption onto eroded PP was increased and the difference between the sorption onto or into the two materials was decreased.

For naphthalene, PE and PP demonstrate similar sorption capacity. Considering this observation one can conclude that naphthalene, although it is the smallest molecule of the three, sorbs onto the surface of the eroded PE and PP pellets. It is the least hydrophobic compound and does not have the driving force to diffuse into the PE or the PP pellets as do the other two PAH compounds. This is corroborated by the early equilibration time ( 28 and 21 days for PE and PP, respectively).

Experimental results are simulated well by the analytical model short-term approximation (Equation 4; see Figure 3 for an example). In Table 1, $D_{a}$ values obtained from the analytical model simulations and calculated $D_{\mathrm{e}} / \mathrm{a}^{2}$ based on the distribution coefficient and polymer density are presented. $D_{\mathrm{a}}$ is the apparent diffusion coefficient that is a measure of overall concentration change in the solution. $D_{\mathrm{e}} / \mathrm{\alpha}^{2}$ is the effective diffusion rate that is independent of distribution coefficient and polymer radius and is a means of comparing materials of various radii and distribution coefficients. $D_{\mathrm{e}} / \alpha^{2}$ is the rate with which the solute diffuses into each material regardless of its properties. For example, a large radius or a higher distribution coefficient would result in a slower $D_{a}$ regardless of the actual rate within the sorbent material. In environmental studies, $D_{\mathrm{a}}$ is a relevant property of the pellets since it measures the disappearance of the solute from the solution whereas in polymer science, $D_{\mathrm{e}} / \mathrm{a}^{2}$ is more relevant.

For naphthalene, effective diffusion rate values in both materials are the same $\left(1 \mathrm{E}^{-5} \mathrm{~s}^{-1}\right)$. For phenanthrene, both the diffusion coefficients and the diffusion rates are similar with those of pyrene. For PE and these two compounds, both apparent diffusion and effective diffusion rates are lower than those for PP. In Karapanagioti and Klontza (2008), phenanthrene effective diffusion rate was the same for both virgin PE and PP. Phenanthrene diffusion rate into eroded PE in the present study is comparable with that of eroded PE $\left(3 \mathrm{E}^{-6} \mathrm{~s}^{-1}\right)$ in Karapanagioti and Klontza (2008) and is slower than that of virgin PE $\left(1 \mathrm{E}^{-5} \mathrm{~s}^{-1}\right)$. This could be due to changes in morphology caused by erosion that increases PE crystallinity (Satoto et al., 1997; Guadagno et al., 2001) and density (Gulmine et al., 2003). As described in the polymer science literature review in Young and Weber (1995), polymers with increased crystallinity are expected to have slower diffusion kinetics and increased distribution coefficient for organic sorbates. These two sorptive behavior characteristics are observed for the eroded pellets when compared to virgin PE tested. 


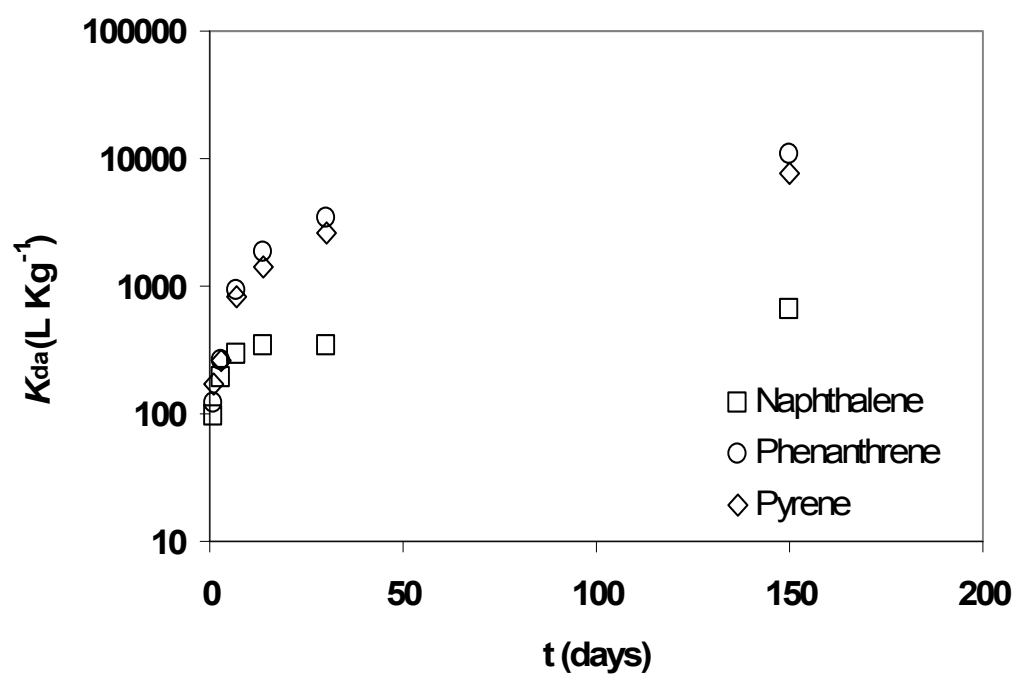

Figure 1. Sorption kinetic curves for 3 PAH compounds and PE pellets. $K_{\mathrm{da}}$ is the apparent sorption distribution coefficient measured at a given time

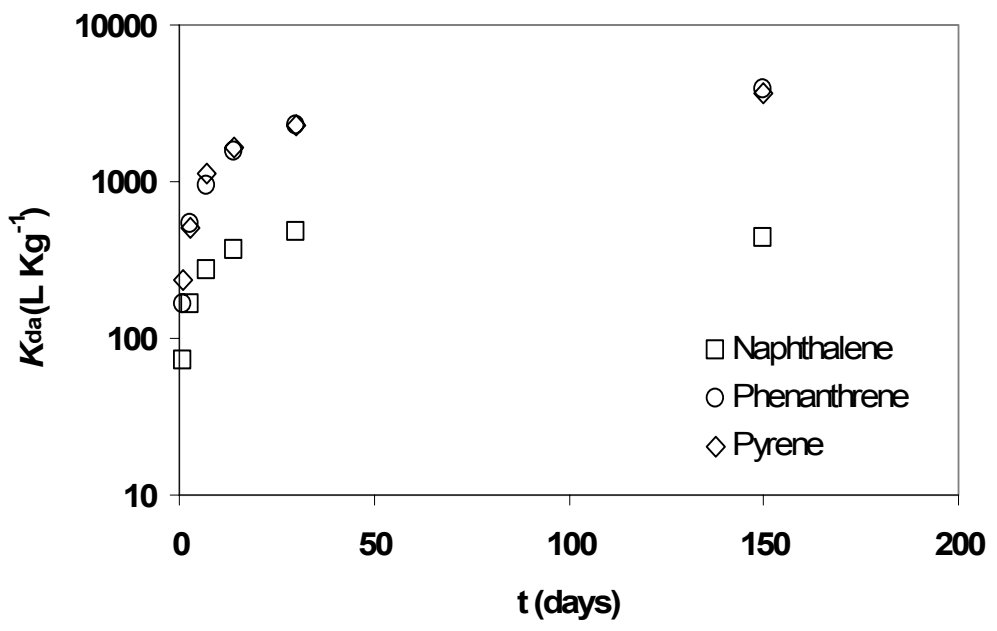

Figure 2. Sorption kinetic curves for $3 \mathrm{PAH}$ compounds and PP pellets. $K_{\mathrm{da}}$ is the apparent sorption distribution coefficient measured at a given time

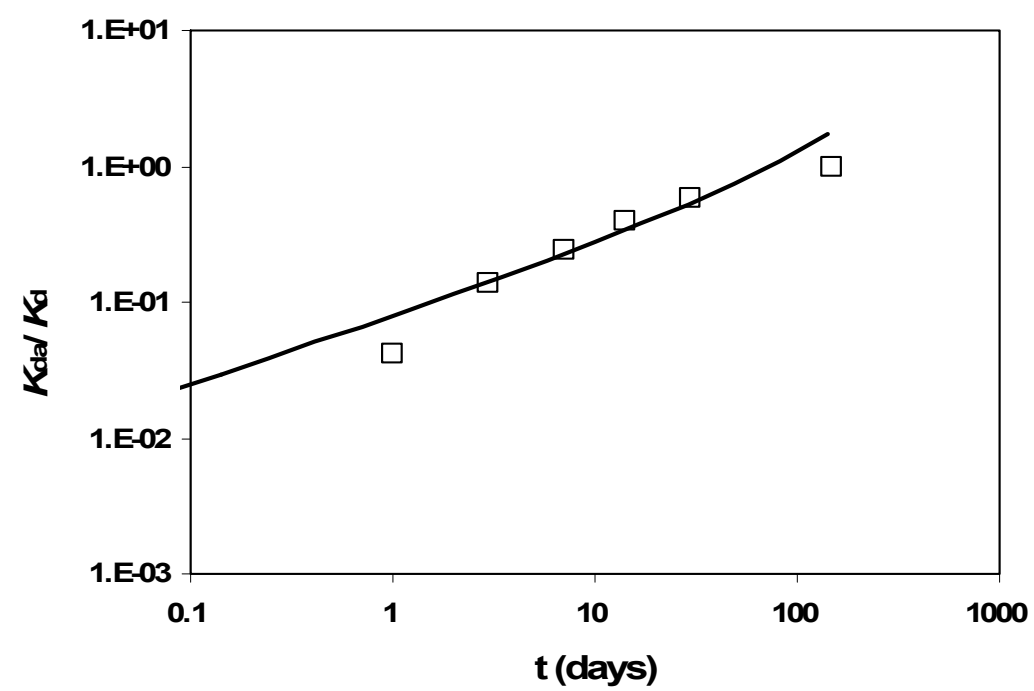

Figure 3. Phenanthrene distribution kinetic experimental results (squares) and analytical model predictions (solid line) for eroded polypropylene (PP). $K_{\mathrm{da}}$ : apparent distribution coefficient measured at a given time over $K_{d}$ : distribution coefficient at equilibrium 
D'Aniello et al. (2000) observed slower diffusion for PP with increased crystallinity. Phenanthrene apparent diffusion coefficient for eroded PP in the present study is slower than that for virgin PP (3 $\left.\mathrm{E}^{-10} \mathrm{~s}^{-1}\right)$ in Karapanagioti and Klontza (2008) whereas the diffusion rate is similar $\left(1 \mathrm{E}^{-5} \mathrm{~s}^{-1}\right)$. Thus, diffusion into eroded PP seems slower but actually is the same (of the same rate) but more surface is available for sorption or surface diffusion (this is also corroborated by the higher sorption capacity into the eroded PP).

Table 1. Kinetic distribution properties based on analytical modeling

\begin{tabular}{lccccc}
\hline Sorbent - Sorbate & $\begin{array}{c}\alpha \\
(\mathbf{c m})\end{array}$ & $\begin{array}{c}\mathbf{D}_{\mathbf{a}} \\
\left(\mathbf{c m}^{2} \mathbf{s}^{-1}\right)\end{array}$ & $\begin{array}{c}\boldsymbol{D}_{\mathrm{e}} / \mathbf{\alpha}^{2} \\
\left(\mathbf{s}^{-1}\right)\end{array}$ & $\mathbf{T ~ ( 9 0 \% )}$ & error \\
\hline PE-Naphthalene & 0.14 & $4 \mathrm{E}^{-10}$ & $1 \mathrm{E}^{-5}$ & 28 & 0.68 \\
\hline PE-Phenanthrene & 0.14 & $1 \mathrm{E}^{-11}$ & $5 \mathrm{E}^{-6}$ & 105 & 1.00 \\
\hline PE-Pyrene & 0.14 & $2 \mathrm{E}^{-11}$ & $7 \mathrm{E}^{-6}$ & 128 & 0.45 \\
\hline PP-Naphthalene & 0.10 & $3 \mathrm{E}^{-10}$ & $1 \mathrm{E}^{-5}$ & 21 & 0.64 \\
\hline PP-Phenanthrene & 0.10 & $6 \mathrm{E}^{-11}$ & $2 \mathrm{E}^{-5}$ & 63 & 0.24 \\
\hline PP-Pyrene & 0.10 & $6 \mathrm{E}^{-11}$ & $2 \mathrm{E}^{-5}$ & 49 & 0.61 \\
\hline
\end{tabular}

PE: polyethylene; PP: polypropylene; $\boldsymbol{\alpha}$ : particle radius; $\boldsymbol{D}_{\mathrm{a}}$ : apparent diffusion coefficient (value chosen to minimize model error); $\boldsymbol{D}_{\mathrm{e}} / \boldsymbol{\alpha}^{2}$ : effective diffusion rate; T (90\%): time required to reach $90 \%$ equilibrium expressed in days; error: the $\Sigma[$ (mean of measurement - model prediction) / model prediction $^{2}$ of all measurements

Such comparisons are possible only in kinetic experiments or when distribution equilibrium is reached. For measurements of contaminant concentrations in field pellets there is no indication where each pellet may be on the kinetic curve at the time of sampling. Yellowing is used as such an indication and statistics (use of 5 pools and then choosing the median as the appropriate value) are employed to overcome this problem. In the present study, the measurements from pellets and literature data are used to determine whether such kinetic studies are relevant in understanding the contaminant concentration measurements of the pellets.

Table 2 presents the concentration of PAHs measured in yellowed PE sampled from two locations in Saronikos Gulf and literature corresponding seawater concentrations from similar locations. Table 3 presents the octanol water distribution coefficient $\left(K_{\mathrm{ow}}\right)$ of the PAH compounds, the $K_{\mathrm{da}}$ values calculated based on data from Table 2, and their fractions. Assuming that $K_{\text {ow }}$ simulates $K_{d}$ their fraction simulates the degree of equilibrium attained for each PAH and each location. The degree of equilibrium attained for each PAH is different between the two sites. This difference is not uncommon for environmental samples and also considering that the measurements found in the literature were performed at different times and by different research teams (Valavanidis et al., 2008). PAHs with molecular weights 178 and 202 reached around $1 \%$ of equilibrium in Loutropyrgos beach and $0.4 \%$ in Aegena island. PAHs with molecular weight of 252 reached $10^{-4}$ of equilibrium in Loutropyrgos beach and $10^{-5}$ in Aegena island. Much lower concentrations of PAHs in the pellets can be partly ascribed to photodegradation of PAHs because they are always exposed to sunlight due to floating of the pellets. For these two sites, these observations mean that in order to consider the one sampling site more or less polluted than the other the difference of the concentration of lower molecular weight PAHs in the pellets has to be higher than 4 and of higher molecular weight PAHs higher than one order of magnitude. In any case, considering both the results from the pellets and also from the seawater literature data, Loutropyrgos beach is more polluted by PAHs than Aegena island.

If the goal is to identify the source of PAH pollution the ratios of phenanthrene to anthracene and fluoranthene to pyrene are appropriate to be calculated. Both in plastic pellets and in seawater the phenanthrene to anthracene ratio is lower than 10 and the fluoranthene to pyrene is higher than 1 (Budzinski et al., 1997). Both these ratios suggest that PAHs are from pyrogenic origin. Considering these, one can conclude that with careful interpretation, pellets can be used to compare pollution and also identify the source of the pollutants at different sites. 
Table 2. Concentration of PAHs measured in pellets sampled from two locations in Saronikos Gulf and literature corresponding seawater (SW) concentrations from similar locations (Valavanidis et al., 2008)

\begin{tabular}{lcccc}
\hline Sampling Site & $\begin{array}{c}\text { Loutropyrgos } \\
\text { beach }\end{array}$ & $\begin{array}{c}\text { Aegena } \\
\text { island }\end{array}$ & $\begin{array}{c}\text { Loutropyrgos } \\
\text { beach }\end{array}$ & $\begin{array}{c}\text { Aegena } \\
\text { island }\end{array}$ \\
\hline PAH & $\mathbf{n g ~ g}^{-1}$ of pellet & \multicolumn{2}{c}{$\mathbf{n g ~ L}^{-1} \mathbf{S W}^{*}$} \\
\hline Phenanthrene & 34 & 21 & 78 & 54 \\
\hline Anthracene & 36 & 2.7 & 28 & 30 \\
\hline Fluoranthene & 86 & 9.8 & 66 & 34 \\
\hline Pyrene & 36 & 5.5 & 25 & 18 \\
\hline $\begin{array}{l}\text { Benzo[b] } \\
\text { fluoranthene }\end{array}$ & 5.3 & 2.3 & 26 & 55 \\
\hline Benzo[a]pyrene & 3 & 2.8 & 20 & 25 \\
\hline
\end{tabular}

Table 3. Molecular weight and distribution coefficients

\begin{tabular}{|c|c|c|c|c|c|c|}
\hline Sampling Site & & & $\begin{array}{c}\text { Loutropyrgos } \\
\text { beach }\end{array}$ & $\begin{array}{l}\text { Aegena } \\
\text { island }\end{array}$ & $\begin{array}{c}\text { Loutropyrgos } \\
\text { beach }\end{array}$ & $\begin{array}{l}\text { Aegena } \\
\text { island }\end{array}$ \\
\hline PAH & MW & $K_{\text {ow }}$ & $K_{\mathrm{da}}$ & $K_{\mathrm{da}}$ & $K_{\mathrm{da}} / K_{\mathrm{ow}}$ & $K_{\text {da }} / K_{\text {ow }}$ \\
\hline Phenanthrene & 178 & 40000 & 440 & 390 & 0.011 & 0.0098 \\
\hline Anthracene & 178 & 32000 & 1300 & 90 & 0.041 & 0.0028 \\
\hline Fluoranthene & 202 & 79000 & 1300 & 290 & 0.016 & 0.0036 \\
\hline Pyrene & 202 & 76000 & 1400 & 310 & 0.019 & 0.0040 \\
\hline $\begin{array}{l}\text { Benzo[b] } \\
\text { fluoranthene }\end{array}$ & 252 & 1100000 & 190 & 42 & 0.00018 & 0.00004 \\
\hline Benzo[a]pyrene & 252 & 1100000 & 150 & 110 & 0.00013 & 0.00009 \\
\hline
\end{tabular}

\section{CONCLUSIONS}

Plastic pellets are possible passive samplers of the diffuse pollution in an area. Conducting experiments with eroded plastic pellets provides insight of the sorptive behavior of the pellets and the organic compounds used. Since each compound has a different behavior, using plastic pellets require a well-defined knowledge of the sorption mechanism for each compound. Furthermore, understanding the sorption behavior of the eroded pellets provides explanations for the results observed when using both PE and PP as passive samplers.

\section{ACKNOWLEDGEMENTS}

A. Christopoulou from the University of Patras provided technical assistance for the kinetic sorption experiments. Dr. S. Endo from Helmholtz Centre for Environmental Research - UFZ, Germany sampled the plastic pellets from Aegena island and provided helpful comments on the manuscript. The kinetic sorption experiments were performed at the Laboratories of Catalysis and Interfacial Chemistry Research Group and Analytical Chemistry Research Group in the University of Patras.

\section{REFERENCES}

Azzarello M.Y. and Van Vleet E.S. (1987) Marine Birds and Plastic Pollution, Mar. Ecol. Progr. Ser., 37, 295-303.

Budzinski H., Jones I., Bellocq J., Pierard C. and Garrigues P. (1997) Evaluation of sediment contamination by polycyclic aromatic hydrocarbon in the Gironde estuary, Marine Chemistry 58, 8597.

Cornelissen G. and Gustafsson O. (2004) Sorption of Phenanthrene to Environmental Black Carbon in Sediment with and without Organic Matter and Native Sorbates, Environmental Science and Technology, 38, 148-155.

D'Aniello C., Guadagno L., Gorrasi G. and Vittoria V. (2000) Influence of the crystallinity on the transport properties of isotactic polypropylene, Polymer, 41, 2515-2519.

Derraik G.B.J. (2002) The pollution of the marine environment by plastic debris: a review, Marine Pollution Bulletin, 44, 842-852. 
Endo S., Takizawa R., Okuda K., Takada H., Chiba K., Kanehiro H., Ogi H., Yamashita R. and Date T. (2005) Concentration of polychlorinated biphenyls (PCBs) in beached resin pellets: Variability among individual particles and regional differences, Marine Pollution Bulletin, 50, 1103-1114.

Grathwohl P. (1998) Diffusion in Natural Porous Media, Kluwer Academic Publishers, Boston.

Guadagno L., Naddeo C., Vittoria V., Camino G. and Cagnani G. (2001) Chemical and morphological modifications of irradiated linear low density polyethylene (LLDPE), Polymer Degradation and Stability, 72, 175-186.

Gulmine J.V., Janissek P.R., Heise H.M. and Akcelrud L. (2003) Degradation profile of polyethylene after artificial accelerated weathering, Polymer Degradation and Stability, 79, 385-397.

Karapanagioti H.K., Siavalas G., Kalaitzidis S., Papatheodorou G. and Christanis K. (2009) Distribution of polycyclic aromatic hydrocarbons (PAHs) in the Gulf of Aliveri, Central Greece, In: Proceedings of the $9^{\text {th }}$ National Greek Symposium on Oceanography and Fishery, Patras, 1, 251-255.

Karapanagioti H.K. and Klontza I. (2008) Testing phenanthrene distribution properties of virgin plastic pellets and plastic eroded pellets found on Lesvos island beaches (Greece), Marine Environmental Research, 65, 283-290.

Karapanagioti H.K. and Klontza I. (2007) Investigating the properties of plastic resin pellets found in the coastal areas of Lesvos island, Global NEST Journal, 9, 71-76.

Kostopoulou M., Mylona A., Nikolaou A., Lofrano B., Meric S. and Belgiorno B. (2007) Determination of the aromatic polycyclic hydrocarbons in the harbour sediments of Mytilene, Greece, In: Proceedings of the $10^{\text {th }}$ International Conference on Environmental Science and Technology, Kos island, Greece, September 5-7.

Lipiatou E. and Saliot A. (1991) Fluxes and transport of anthropogenic and natural polycyclic aromatic hydrocarbons in the western Mediterranean Sea, Marine Chemistry, 32, 51-71.

Mato Y., Isobe T., Takada H., Kanehiro H., Ohtake C. and Kaminuma T. (2001) Plastic Resin Pellets as a Transport Medium for Toxic Chemicals in the Marine Environment, Environ.Sci. and Technol., 35, 319324.

Moser M.L. and Lee D.S. (1992) A fourteen year study of plastic ingestion by western North Atlantic seabirds, Colonial Waterbirds, 15, 83-94.

Ogata Y., Takada H., Mizukawa K., Hirai H., Iwasa S., Endo S., Mato Y., Saha M., Okuda K., Nakashima A., Murakami M., Zurcher N., Booyatumanondo R., Zakaria M.P., Dung L.Q., Gordon M., Miguez C., Suzuki S., Moore C.J., Karapanagioti H.K., Weerts S., McClurg T., Burresm E., Smith W., Van Velkenburg M., Lang J.S., Lang R.C., Laursen D., Danner B., Stewardson N. and Thompson R.C. (2009) International Pellet Watch: Global monitoring of persistent organic pollutants (POPs) in coastal waters. 1. Initial phase data on PCBs, DDTs, and HCHs, Marine Pollution Bulletin, 58, 1437-1446.

Sakellarides T.M., Konstantinou I.K., Hela D.G., Lambropoulou D., Dimou A. and Albanis T.A. (2006) Accumulation profiles of persistent organochlorines in liver and fat tissues of various waterbird species from Greece, Chemosphere, 63, 1392-1409.

Satoto R., Subowo W.S., Yusiasih R., Takane Y., Watanabe Y. and Hatakeyama T. (1997) Weathering of high-density polyethylene in different latitudes, Polymer Degradation and Stability, 56, 275-279.

Stefanelli P., Di Muccio A., Ferrara F., Barbini D.A., Generali T., Pelosi P., Amendola G., Vanni F., Di Muccio S. and Ausili A. (2004) Estimation of intake of organochlorine pesticides and chlorobiphenyls through edible fishes from the Italian Adriatic Sea during 1997, Food Control, 15, 27-38.

Valavanidis A., Vlachogianni Th., Triantafillaki S., Dassenakis M., Androutsos F. and Scoullos M. (2008) Polycyclic aromatic hydrocarbons in surface seawater and in indigenous mussels (Mytilus galloprovincialis) from coastal areas of the Saronikos Gulf (Greece), Estuarine, Coastal and Shelf Science, 79, 733-739.

Young T.M. and Weber-Jr.W.J. (1995) A distributed reactivity model for sorption by soils and sediments 3. Effects of diagenetic processes on sorption energetics, Environmental Science and Technology, 29, 92-97. 